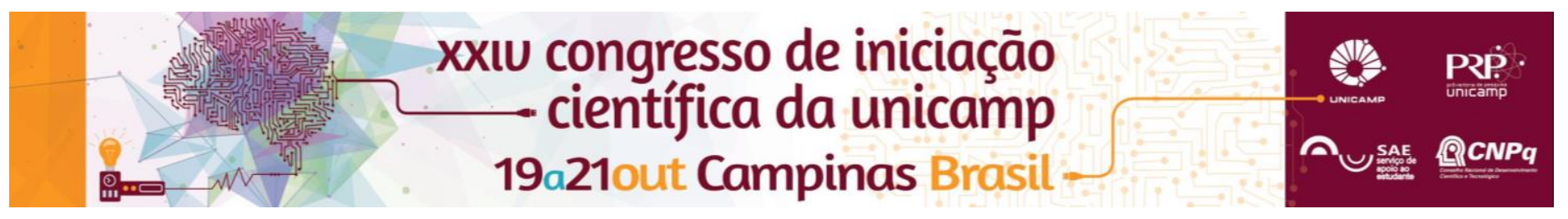

\title{
Necessidades odontológicas de pacientes oncológicos
}

\author{
Marina M. Moraghi, Marcio A. Lopes
}

\section{Resumo}

A radioterapia e a quimioterapia são de extrema importância no tratamento de pacientes oncológicos, mas em contrapartida trazem inúmeras complicações para quem as faz. Sendo assim, é de extrema importância a avaliação odontológica para prevenir e/ou minimizar esses danos.

\section{Palavras-chave: \\ Câncer, radioterapia, tratamento odontológico.}

\section{Introdução}

A condição bucal pode interferir no tratamento oncológico, assim como o tratamento oncológico pode interferir na condição bucal. Assim, a promoção de saúde bucal contribui de maneira significativa quer seja na continuidade do tratamento oncológico, quer seja na prevenção, diagnóstico e tratamento de efeitos colaterais bucais e ou sistêmicos.

O tratamento odontológico deve ser iniciado, de preferência, antes da oncoterapia e permanecer durante e após o término desta. O objetivo desse tratamento é eliminar ou estabilizar as condições bucais para minimizar as infecções locais e sistêmicas, reduzir a dor, favorecer a alimentação via oral, evitando ou reduzindo o tempo de internação desses pacientes, melhorando assim sua qualidade de vida.

\section{Resultados e Discussão}

O levantamento feito para o presente trabalho mostrou que de 104 prontuários analisados, apenas 64 estavam dentro dos critérios de inclusão do estudo, pois 24 prontuários não apresentavam as informações necessárias e 16 eram de pacientes desdentados.Com relação ao momento da avaliação odontológica, a maioria dos pacientes analisados realizaram apenas avaliação pré tratamento oncológico, correspondendo a 30 pacientes $(46,87 \%)$. Outros 25 pacientes $(39,06 \%)$ realizaram avaliação odontológica pré e pós tratamento oncológico e $9(14,07 \%)$ realizaram apenas avaliação odontológica pós tratamento oncológico. Quando levado em consideração a idade, o gênero e a cor da pele, foi observado que a maioria dos pacientes estão entre a faixa etária de 61 a 70 anos $(29,69 \%)$, são do gênero masculino $(79,69 \%)$ e da cor branca $(68,75 \%)$. A maioria $(37,50 \%)$ eram exfumantes e ex - etilistas (34,30\%). Com relação ao tipo de queixa $(57,81 \%)$ foram encaminhados ao serviço para realização de avaliação pré-radioterapia. Os pacientes foram também classificados de acordo com a localização do tumor primário, e a maior parte deles $(18,75 \%)$ tinham tumor primário na laringe. Levando em consideração a necessidade odontológica pré tratamento oncológico (34,38\%), a maioria necessitava apenas de exodontia. Já quanto as necessidades odontológicas pós tratamento oncológico, apenas 34 dos 64 pacientes passaram por avaliação odontológica pós tratamento oncológico e desses a maior parte $(8,81 \%)$ precisavam de exodontia ou orientação de higiene bucal ou prótese parcial removível. A última informação retirada do prontuário de cada paciente foi a situação que o paciente se encontra no momento da última informação, 52 pacientes $(81,25 \%)$ estão em tratamento, 8 pacientes (12,50 \%) foram perdidos de vista, 2 pacientes $(3,125 \%)$ foram mortos pela doença e 2 pacientes $(3,125 \%)$ morreram durante o tratamento.

\section{Conclusões}

Com o presente estudo observamos que o tratamento odontológico antes, durante e após o tratamento oncológico, melhora a condição de vida dos pacientes minimizando os riscos de infecção local e sistêmica. O tipo mais comum de necessidade pré tratamento oncológico é a exodontia, sendo observada na quase totalidade dos pacientes. As complicações odontológicas durante o tratamento são significativamente diminuídas naqueles pacientes que foram submetidos a avaliação odontológica prévia. Com isso conclui-se que a participação do cirurgião dentista em uma equipe multidisciplinar que trata de pacientes com câncer é de extrema importância.

\section{Agradecimentos}

Insira aqui seu agradecimento e/ou informar a Instituição de fomento, se houver. Use fonte Arial 10. Caso não possua, exclua este campo.

1 Bradford Teaching Hospitals NHS Foundation Trust, Bradford, UK. Oral and dental management for head and neck cancer patients treated by chemotherapy and radiotherapy. Dent Update. 2012 Mar;39(2):135-8, 140. ${ }^{2}$ Beumer $\mathrm{J}$ 3rd, Cutis T, Harrison RE. Radiation therapy of the oral cavity: sequelae and management, part 1 . Head Neck Surg. 1979; 1 (4): 301-12.

${ }^{3}$ Blozis GG, Robinson JE. Oral tissue changes caused by radiation therapy and their management. Dent Clin Nort Am. 1968 ; Nov: 643-56. 